\title{
Conference Paper \\ Poly(vinyl alcohol): Physical Approaches to Designing Biomaterials for Biomedical Applications
}

\author{
Shathani Nkhwa, Kristo Fernando Lauriaga, Evren Kemal, and Sanjukta Deb \\ Department of Biomaterials, King's College London Dental Institute, Floor 17, Tower Wing, \\ London SE1 9RT, UK \\ Correspondence should be addressed to Sanjukta Deb; sanjukta.deb@kcl.ac.uk
}

Received 22 November 2013; Accepted 12 February 2014; Published 20 March 2014

Academic Editors: J. Gough and R. Sammons

This Conference Paper is based on a presentation given by Shathani Nkhwa at "UK Society for Biomaterials Annual Conference 2013” held from 24 June 2013 to 25 June 2013 in Birmingham, United Kingdom.

\begin{abstract}
Copyright (C) 2014 Shathani Nkhwa et al. This is an open access article distributed under the Creative Commons Attribution License, which permits unrestricted use, distribution, and reproduction in any medium, provided the original work is properly cited.

Poly(vinyl alcohol) is a non-toxic, biosynthetic polymer and biocompatible polymer that has the ability to form hydrogels either via chemical or physical crosslinking. Whilst chemical crosslinking provides greater control on the properties of the resultant hydrogel, physically crosslinked hydrogels or blends with other biocompatible polymers are more suited for biomedical applications. In this paper we report a systematic study on the effect of varying concentrations of PVA, physical methods of crosslinking, and PVAgelatin and PVA-PVP blends on the physical and mechanical properties of the hydrogels.
\end{abstract}

\section{Introduction}

In the last few decades there has been a growing interest in biocompatible and biodegradable polymers that are being used to create scaffolds for tissue engineering. To design scaffolds for tissue engineering, the main requirements are high porosity, interconnected porous structure, large surface area, and a microenvironment that allows the cells to adhere, proliferate, differentiate, and retain its phenotype. It is well established that interconnected pores play an important role in cell engineering; however, with increasing porosity there is an inevitable loss in the mechanical properties. A large number of different polymers including hydrogels have been explored for different tissue engineering applications [1]. Poly(vinyl alcohol) is a water soluble, nontoxic, biocompatible polymer that is able to exhibit hydrogen bonding by virtue of the hydroxyl groups present in the repeating units. PVA can form hydrogels either via chemical or physical crosslinking, which exhibit high water content. It can be chemically crosslinked with radiation or aldehydes to form hydrogels using chemicals such as glutaraldehyde, methanol, ethanol, propranolol, and acetone. However, many of these chemicals are not cytocompatible making it an unsuitable method despite being usually cheap and efficient [2-7]. Physical crosslinking methods such as air-drying and cryogelation by repeated freeze-thawing cycles of the aqueous polymer solutions are more biologically compatible but do not allow for the level of control available with other crosslinking methods [8]. PVA three-dimensional networks are of considerable interest in biomaterial applications as the materials can be engineered to closely match human tissues. There has been a significant interest in the cryogenic gelation of PVA as a method of producing hydrogels for biomedical applications. Cryogenic gelation of PVA can lead to a porous structure and the ability for these polymers to absorb surrounding fluid, thus making them attractive candidates for tissue engineering. Furthermore, PVA blends of poly(vinyl pyrrolidone, PVP), gelatin, alginates, collagen and composites with calcium phosphates have been reported for potential use as scaffolds for bone tissue engineering. It is generally accepted that PVA chains can undergo crosslinking via a freeze-thaw process and the degree of crosslinking increases with the number of cycles, whilst the equilibrium water uptake can be altered either via physical crosslinking or by blending with other polymers. 
TABLE 1: Composition ratios of 10\% PVA and 5\% gelatin stock solutions in each PVA : gelatin hydrogel blends.

\begin{tabular}{lcc}
\hline $10 \%$ PVA & $5 \%$ gelatin & \%PVA in blend \\
\hline 20 & 0 & $100 \%$ \\
16 & 4 & $80 \%$ \\
12 & 8 & $60 \%$ \\
8 & 12 & $40 \%$ \\
4 & 16 & $20 \%$ \\
\hline
\end{tabular}

Despite a large number of studies on PVA for biomedical applications, there is a lack of dedicated and systematic study of the properties of physically crosslinked PVA hydrogels. Our ultimate goal is to create composite scaffolds of PVA hydrogels that can in addition function as a carrier for growth factors and/or plasma rich platelets for bone growth. Thus in this study, we report the properties of PVA hydrogels crosslinked via facile physical crosslinking methods and PVA blends with gelatin and PVP, to further apply the optimum blends for future composite formulation.

\section{Materials \& Methods}

Poly(vinyl alcohol) (PVA) granules (Merck, UK) of $145,000 \mathrm{~mol} \cdot \mathrm{wt}$. and $\geq 98 \%$ hydrolysis, poly(vinyl pyrrolidone) (PVP) powder (Sigma-Aldrich, UK) and 40,000 mol-wt., Gelatin (FLUKA) were used in this study.

2.1. Preparation of PVA and PVP Solutions. PVA $10 \%, 20 \%$, and $30 \% \mathrm{w} / \mathrm{v}$ solutions were prepared by dissolution of the appropriate amount of PVA granules in distilled water and mixed in a Duran bottle and magnetically stirred at $121^{\circ} \mathrm{C}$ until all the PVA granules dissolved to form a homogenous solution. Similarly, PVP (5\% w/v) solution was produced by mixing appropriate amount of PVP powder and distilled water and magnetically stirred at room temperature.

2.2. PVA/Gelatin Blend Preparation. Blends were prepared by mixing the required amounts (Table 1 ) and placed in a hot water bath at $50^{\circ} \mathrm{C}$ and solution gently mixed. The blends were then physically cross-linked by 1 freeze thaw cycle, which consisted of first freezing the samples to $-80^{\circ} \mathrm{C}$ for 1 hour in a freezer, then placing it in a (VirTis SP Scientific) freeze dryer at $-59.4^{\circ} \mathrm{C}$ with vacuum set to $17 \mathrm{mT}$ for 24 hours. After freeze drying the samples were thawed at room temperature for 12 hours.

2.3. Preparation of Hydrogel Films. PVA hydrogels were produced through physical crosslinking methods of airdrying only (AD), one cycle of freeze thawing (FT), and both air-drying followed freeze thawing $(\mathrm{AD}+\mathrm{FT})$. Air dried hydrogels were prepared by placing the PVA solutions in Petri dishes at room temperature and left to completely dry over a period of 7 days. Air-dried and freeze thawing specimens were allowed to dry partially and then subjected to the FT cycle as described. PVA: PVP gel blends (see Table 2) were first produced by freeze thawing to study the miscibility between the two polymers. Subsequently, 50:50 and 75:25
TABle 2: Composition ratios of 10\% PVA and 5\% PVP stock solutions in each PVA : PVP hydrogel blends.

\begin{tabular}{lcc}
\hline Name & 10\% PVA composition & 5\% PVP composition \\
\hline Control & 100 & 0 \\
$75: 25$ & 75 & 25 \\
$50: 50$ & 50 & 50 \\
$25: 75$ & 25 & 75 \\
Control 2 & 0 & 100 \\
\hline
\end{tabular}

mix ratios were air-dried only to create hydrogels sheets for tensile testing.

2.4. Fourier Transform Infrared (FTIR). Fourier transform infrared spectroscopy was carried out using a Perkin Elmer precisely spectrum FTIR spectrometer. FTIR spectra were obtained in the wavenumber range of $650-3500 \mathrm{~cm}^{-1}$ with $4 \mathrm{~cm}^{-1}$ resolution.

2.5. Equilibrium Water Uptake. The dried gels were cut in rectangular strips and weighed accurately prior to immersing them in distilled water at $37^{\circ} \mathrm{C}$. After immersion the samples were periodically weighed by removing them and gently pressed between filter paper and the process was continued until there were no further gravimetric changes. The equilibrium water content (EWC) (\%) was calculated using the following equation:

$$
\mathrm{EWC}=\left[\frac{W_{s}-W_{d}}{W_{s}}\right] \times 100,
$$

wherein $W_{s}$ is hydrated weight when swollen and $W_{d}$ is the dry weight of hydrogel prior to swelling.

2.6. Tensile Testing. All hydrogel films were cut into standard dumbbell shapes and swollen to equilibrium state before testing. The tensile tests were carried out at rate of $5 \mathrm{~mm} / \mathrm{min}$ using a Universal testing machine (Instron 5569A).

2.7. Differential Scanning Calorimetry (DSC). A Perkin Elmer Jade series differential scanning calorimeter was used to determine the thermal properties and Perkin Elmer Jade series software to process raw data. 10-20 mg samples were carefully placed and sealed in aluminium pans (Perkin Elmer). The scans were carried out with reference pan calibrated using Indium ${ }^{49}$ under a Nitrogen ${ }^{7}$ atmosphere. Two cycles of heating and cooling were carried out, starting from $-20^{\circ} \mathrm{C}$ to $200^{\circ} \mathrm{C}$ followed by a cooling cycle to $0^{\circ} \mathrm{C}$ at a rate of $10^{\circ} \mathrm{C}$ per minute. The temperature of the second heating cycle was raised to $280^{\circ} \mathrm{C}$ and the same cooling cycle followed. The glass transition temperature $\left(T_{g}{ }^{\circ} \mathrm{C}\right)$ and melting temperature $\left(T_{m}{ }^{\circ} \mathrm{C}\right)$ were calculated using the Pyris Jade DSC (Perkin Elmer) software.

\section{Results and Discussion}

3.1. Equilibrium Water Uptake. The dissolution of PVA is essential to form physical hydrogels. The dissolution of PVA 
TABLE 3: Equilibrium water uptake of the different hydrogel films prepared by one cycle freeze-thaw (1FT), air-dried and one cycle freeze-thaw $(\mathrm{AD}+1 \mathrm{FT})$ and air dried $(\mathrm{AD})(n=3)$.

\begin{tabular}{|c|c|c|}
\hline Crosslinking method & Hydrogel & EWC\% \\
\hline \multirow{9}{*}{$1 \mathrm{FT}$} & PVA10 & $73.52 \pm 0.30$ \\
\hline & PVA20 & $69.06 \pm 0.30$ \\
\hline & PVA30 & $66.72 \pm 2.71$ \\
\hline & 75 PVA : 25 PVP & $83.07 \pm 1.02$ \\
\hline & 50 PVA : 50 PVP & $85.22 \pm 0.64$ \\
\hline & 80 PVA : 20 gelatin & $82.19 \pm 0.83$ \\
\hline & 60 PVA : 40 gelatin & $80.44 \pm 0.48$ \\
\hline & 40 PVA : 60 gelatin & $79.08 \pm 3.67$ \\
\hline & 20 PVA : 80 gelatin & $85.39 \pm 1.81$ \\
\hline \multirow{3}{*}{$\mathrm{AD}+1 \mathrm{FT}$} & PVA10 & $69.62 \pm 4.46$ \\
\hline & PVA20 & $60.71 \pm 1.77$ \\
\hline & PVA30 & $63.49 \pm 1.44$ \\
\hline \multirow{7}{*}{$\mathrm{AD}$} & PVA10 & $65.63 \pm 1.10$ \\
\hline & PVA20 & $53.71 \pm 2.56$ \\
\hline & PVA30 & $56.93 \pm 3.32$ \\
\hline & 80 PVA : 20 gelatin & $76.90 \pm 1.35$ \\
\hline & 60 PVA : 40 gelatin & $75.72 \pm 4.74$ \\
\hline & 40 PVA : 60 gelatin & $74.72 \pm 0.90$ \\
\hline & 20 PVA : 80 gelatin & $78.40 \pm 4.32$ \\
\hline
\end{tabular}

in water is dependent on the molecular weight and the degree of hydrolysis of the polymer. It has been reported that high dissolution temperatures are required to dissolve PVA in water, especially if it has a high degree of hydrolysis $[9,10]$ due to the strong intra- and intermolecular hydrogen bonds. However, PVA with low degree of hydrolysis contains too many hydrophobic acetate groups, which renders the polymer too hydrophobic to dissolve in water. In this study we used a 98\% hydrolysed PVA of molecular weight of 145,000 and conducted the dissolution in water at $121^{\circ} \mathrm{C}$ and mechanical agitation to yield clear polymer solutions with ease that did not require prolonged incubation in water. The EWC of the PVA hydrogels are shown in Table 3. Solutions of pure PVA at concentrations of $10 \%, 20 \%$, and $30 \%$ by weight in water were subjected to three different treatments, namely, one cycle of freeze-thaw (1FT), air dried (AD), and air dried followed by one freeze thaw cycle $(\mathrm{AD}+1 \mathrm{FT})$ to form hydrogels. The EWC showed that with increasing concentration of PVA there was a decrease, irrespective of the method used to form the hydrogels. The $20 \%$ and $30 \%$ PVA solutions were highly viscous, thus only $10 \%$ PVA solutions were used for preparation of the blends. The presence of PVP showed higher equilibrium water content than PVA. The PVA10 only control had the lowest EWC of 74\% which increased to 83\% and $85 \%$ in $75 \mathrm{PVA}: 25 \mathrm{PVP}$ and 50PVA : 50PVP showing that EWC increased by adding PVP. The higher EWC and less efficient cross-linking could be attributed to the presence of bulky side groups in PVP that could lead to an increase in the amorphous regions and less cross-linking in the hydrogel blends. Furthermore, the hydrophilic nature of PVP contributes to increasing the ingression of bulk water into the

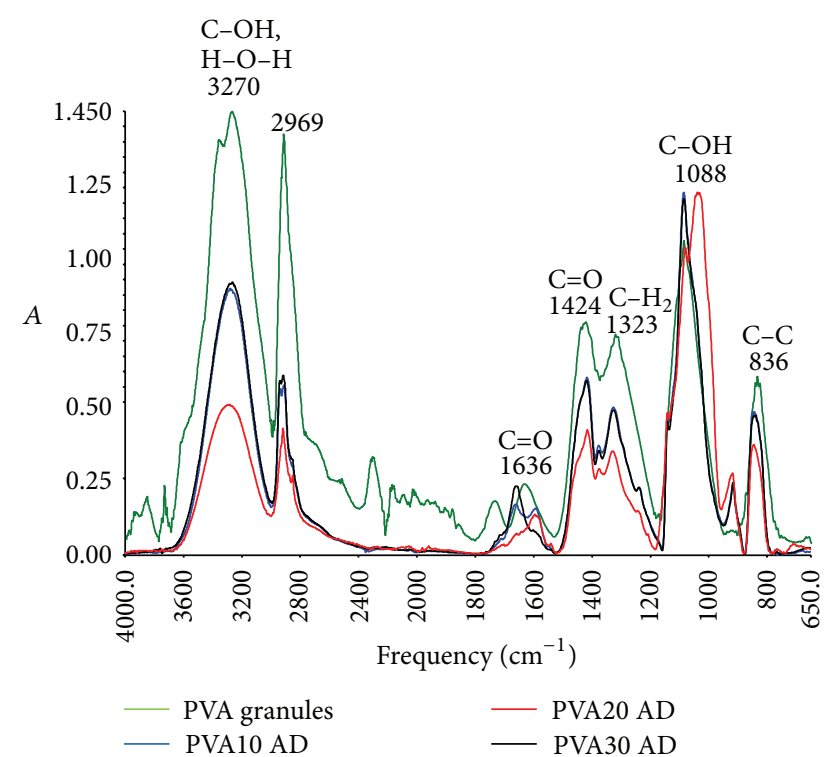

FIGURE 1: A comparison of the infrared absorbance peaks of airdried only PVA10, 20 30\% (w/v) hydrogel films. All three spectra were normalized to allow comparison.

gel matrix and improving interactions with bound water thus leading to the higher EWC.

3.2. FTIR Spectroscopy. A comparison of the FTIR spectra of the three air-dried hydrogels prepared from different concentrations of PVA is shown in Figure 1. All showed characteristic absorption bands of PVA which can be assigned to the vibrations arising due to $\mathrm{C}=\mathrm{O}, \mathrm{C}-\mathrm{H}, \mathrm{C}-\mathrm{OH}, \mathrm{C}-\mathrm{O}$ bonds. A strong characteristic feature of PVA is the $\mathrm{O}-\mathrm{H}$ stretching band indicating the presence of both the strong hydrogen bonding internally to $\mathrm{OH}$ or terminal vinyl $\mathrm{OH}$ groups and broad peaks centred at 3265,3285 , and $3269 \mathrm{~cm}^{-1}$ [11] which were observed for the three hydrogels. Hydroxyl groups from residual water also contribute to the peak intensity [12]. Two strong peaks arising from the $\mathrm{C}-\mathrm{H}$ stretching of the alkyl groups at $2916 \mathrm{~cm}^{-1}$ to $2969 \mathrm{~cm}^{-1}$ are characteristic of the $\mathrm{C}-\mathrm{H}$ symmetric $\left(v_{\mathrm{s}}\right)$ and $\mathrm{CH}_{2}$ asymmetric $\left(v_{\mathrm{as}}\right)$ stretching vibration, with their position suggesting that the hydrocarbon chains of the polymer take a transzigzag conformation. The weak peak at $1595 \mathrm{~cm}^{-1}-1636 \mathrm{~cm}^{-1}$ can be assigned to the $\mathrm{C}=\mathrm{O}$ group from the residual acetate in PVA that results from manufacturing and handling of PVA from hydrolysis of polyvinyl acetate. The peaks arising at $1416 \mathrm{~cm}^{-1}-1424 \mathrm{~cm}^{-1}$ can be assigned to the $-\mathrm{CH}_{2}$ bending with deformation bands of $\mathrm{C}-\mathrm{CH}_{3}$ appearing at $1377 \mathrm{~cm}^{-1}$. The peaks at $1263 \mathrm{~cm}^{-1}$ and $1326 \mathrm{~cm}^{-1}$ are associated with $\mathrm{CH}_{2}$ wagging and the $\mathrm{C}-\mathrm{C}, \mathrm{C}-$ $\mathrm{O}-\mathrm{C}$ stretching vibrations, respectively. The sharp absorption bands indicate that the film formed by this process resulted in a semicrystalline PVA. The peaks at $1038-1088 \mathrm{~cm}^{-1}$ are attributed to $-\mathrm{C}-\mathrm{O}-\mathrm{H}$ bending and $\mathrm{C}-\mathrm{O}$ stretching vibration coupled with $\mathrm{O}-\mathrm{H}$ bending vibration. The atactic form of PVA is also shown by the peaks at $915 \mathrm{~cm}^{-1}\left(\mathrm{CH}_{2}\right.$ rocking) and at $836 \mathrm{~cm}^{-1}-845 \mathrm{~cm}^{-1}$ (C-C stretching) [12-14]. No 


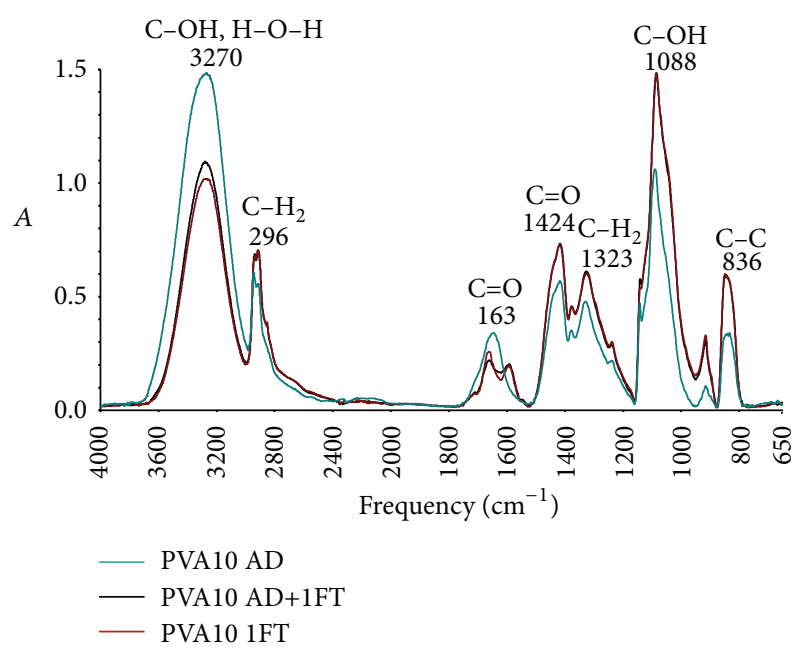

FIGURE 2: A comparison of the infrared absorbance peaks of $10 \%$ PVA (w/v) air-dried only (AD), air-dried and single freeze-thawed $(\mathrm{AD}+1 \mathrm{FT})$, and single freeze-thawed only (1FT) hydrogel films. All three spectra are normalized to allow comparison.

major distinct differences were observed in the spectra; however, in general, broad, high intensity peaks in PVA 30 were noted as possibly arising due to the higher concentration of the polymer.

The FTIR spectra of the PVA-AD, PVA-FT, and PVA$\mathrm{AD}+\mathrm{FT}$ are shown in Figure 2, which indicates that there is a higher degree of crosslinking in the FT and $\mathrm{AD}+\mathrm{FT}$ groups as the peaks associated with $-\mathrm{OH}$ are sharp with lower intensity in comparison to just air dried PVA gel. The stretching of $\mathrm{CH}_{2}$ groups are observed through peaks at $2920 \mathrm{~cm}^{-1}$ (symmetric), $2850 \mathrm{~cm}^{-1}, 1420-1492 \mathrm{~cm}^{-1}$ (bending/scissoring), $1280-$ $1315 \mathrm{~cm}^{-1}$ (wagging), and $1167-1229 \mathrm{~cm}^{-1}$ (twisting) [11]. Stretching of the C-O bonds from primary alcohol groups in PVA can be observed through the peaks at $1050-1095 \mathrm{~cm}^{-1}$ in crosslinked PVA, and this peak is associated more with the aliphatic ethers present in crosslinked polymers.

The FTIR spectra of PVA blends with gelatin and PVP are shown in Figure 3. As expected, there are differences between the spectra of PVA-gelatin, PVP, and PVA. The hydroxyl peaks are also present in the PVP control but it is a broader and much shallower peak centred at $3412 \mathrm{~cm}^{-1}$. This peak could possibly be attributed to hydroxyl groups from the water bound to the PVP polymer chains, and alkyl vibrations are similarly shown by the broad peak centred at 2818 and $1427 \mathrm{~cm}^{-1}$. Most notably the peak at $1651 \mathrm{~cm}^{-1}$ is prominent in the PVP control. This is commonly associated with the carbonyl groups but in the case of PVP it is more likely due to the presence of C-N stretching in PVP [15]. The increase of PVP content in the blend shows a shift in the hydroxyl peak to higher frequencies and a broadening and shallowing of the peak possibly due to the reduction in hydroxyl groups. The narrowing and increasing intensity of the $\mathrm{C}-\mathrm{N}$ peak at $1651 \mathrm{~cm}^{-1}$ is to be expected with the increase in PVP content. The distortions in the peaks at the region around 3290 and $1650 \mathrm{~cm}^{-1}$ are thought to show the strong interaction between the hydroxyl groups of PVA and the carbonyl groups of PVP.

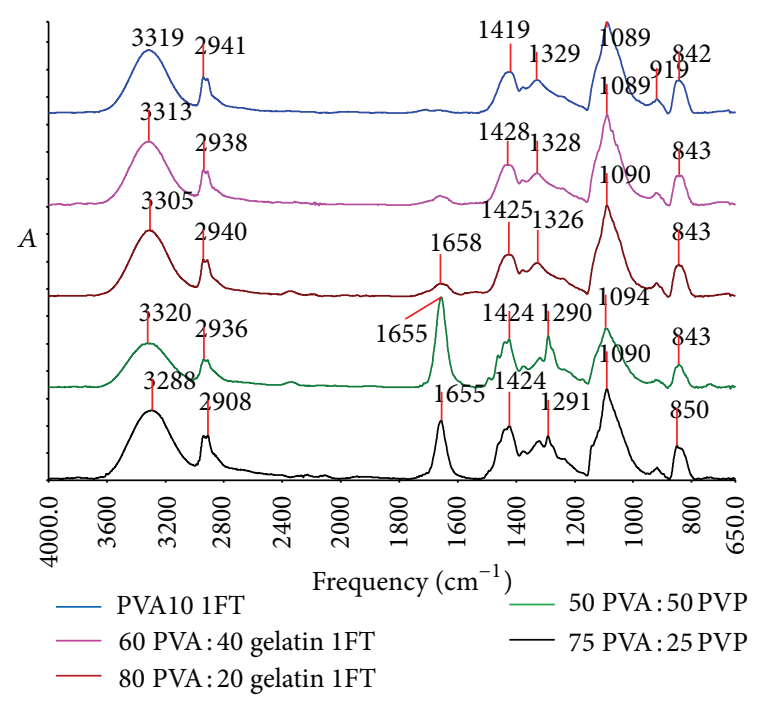

FIGURE 3: A comparison of the infrared absorbance peaks of PVA 10\% (w/v), 60 PVA : 40 gelatin, 60 PVA : 20 gelatin, 50 PVA : 50 PVP, and 75 PVA : 25 PVP, all after 1 cycle of freeze-thawing.

Characteristic bands of gelatin, $\mathrm{NH}$ stretching, amide I, $\mathrm{CO}$, and $\mathrm{CN}$ stretching as well as amide II and amide III can be observed in Figure 3. Amide A with an absorption wavelength of $3296 \mathrm{~cm}^{-1}$ tends to merge with a $\mathrm{CH}_{2}$ stretch peak when carboxylic acid groups exist in intermolecular associations. Amide I bands at $1632 \mathrm{~cm}^{-1}$ have been attributed to intermolecular associations with imide residues. The $\mathrm{CH}_{2}$ bending and wagging vibrations raise two bands at amide II $1535 \mathrm{~cm}^{-1}$ and amide III $1334 \mathrm{~cm}^{-1}$ with final skeletal stretching at both $1080 \mathrm{~cm}^{-1}$ and $638 \mathrm{~cm}^{-1}$ [16-18]. The blends showed characteristic peaks of the components PVA and gelatin and the intensity of the characteristic peak varied with concentration of the components.

3.3. Differential Scanning Calorimetry. The observed glass transition temperature $\left(T_{q}\right)$ and melting temperatures $\left(T_{m}\right)$ of the prepared hydrogels are shown in Table 4 . The first heating cycle of 1FT PVA displayed two endothermic peaks that can be attributed to the loss of moisture or melting of crystallites due to the strong hydrogen bonding between PVA-water and PVA chains themselves [19]. Melting temperatures $\left(T_{m}\right)$ for all the PVA gels stayed comparable and ranged between 220.6 and $227^{\circ} \mathrm{C}$, and the literature $T_{m}$ value for PVA is reported to be $230^{\circ} \mathrm{C}$ which is slightly higher than the observed values [19]. The $T_{g}$ of PVA gels prepared by air drying (AD) $\left(58.0-74.25^{\circ} \mathrm{C}\right)$ was lower with values than those of $\mathrm{AD}+1 \mathrm{FT}$ and $1 \mathrm{FT}\left(61.1-75.2^{\circ} \mathrm{C}, 69.4-73.4^{\circ} \mathrm{C}\right)$, respectively, indicating higher crosslinking occurred with $\mathrm{AD}+1 \mathrm{FT}$ and $1 \mathrm{FT}$ cycle than with just $\mathrm{AD}$. Literature values for $T_{g}$ of PVA have been reported to be around $80^{\circ} \mathrm{C}$ [20] but other studies report a range between $59^{\circ} \mathrm{C}$ and $74^{\circ} \mathrm{C}$ [21]. Thermal analysis of PVA: PVP blends showed $T_{m}$ ranging from 210.5 (25\% PVA) to $229^{\circ} \mathrm{C}(75 \%$ PVA $)$. As expected, no peak was observed in the PVP control as the melting point of PVP is beyond the range of the DSC cycle used. It can also be observed that $T_{g}$ 
TABLE 4: Glass transition $\left(T_{g}\right)$ and melting temperatures $\left(T_{m}\right)$ of different crosslinked materials of PVA $10 \%, 20 \%$, and $30 \%(\mathrm{w} / \mathrm{v})$ blends of PVA $10 \%(\mathrm{w} / \mathrm{v})$ with PVP $5 \%(\mathrm{w} / \mathrm{v})$ and gelatin $5 \%(\mathrm{w} / \mathrm{v})$ after a single freeze-thaw cycle. The $T_{g}$ and $T_{m}$ were obtained from the second cycle.

\begin{tabular}{|c|c|c|c|}
\hline \multicolumn{4}{|c|}{ DSC RESULTS } \\
\hline \multicolumn{2}{|l|}{ Sample name } & $\left(T_{g}{ }^{\circ} \mathrm{C}\right)$ & $\left(T_{m}{ }^{\circ} \mathrm{C}\right)$ \\
\hline \multicolumn{2}{|l|}{ Commercial PVA granules } & 69.6 & 226.2 \\
\hline \multirow{3}{*}{ Air-dried (AD) } & $10 \% P V A$ & 74.25 & 228.1 \\
\hline & $20 \% P V A$ & 61.1 & 220.6 \\
\hline & $30 \%$ PVA & 58.0 & 226.4 \\
\hline \multirow{3}{*}{$\begin{array}{l}\text { Air-dried and one cycle } \\
\text { freeze thawed }(\mathrm{AD}+1 \mathrm{FT})\end{array}$} & $10 \% P V A$ & 75.2 & 226.5 \\
\hline & $20 \%$ PVA & 67.3 & 225.0 \\
\hline & $30 \%$ PVA & 61.1 & 222.2 \\
\hline \multirow{3}{*}{$\begin{array}{l}\text { One cycle freeze thawed } \\
\text { (1FT) }\end{array}$} & $10 \%$ PVA & 73.4 & 227.0 \\
\hline & $20 \% P V A$ & 72.4 & 226.8 \\
\hline & $30 \% P V A$ & 70.5 & 227.0 \\
\hline \multirow{4}{*}{$\begin{array}{l}10 \% \text { PVA and 5\% PVP } \\
\text { blend (1FT) }\end{array}$} & $0 \%$ PVA & 148.5 & No peak \\
\hline & $25 \% P V A$ & 112.7 & 208.6 \\
\hline & $50 \%$ PVA & 109.0 & 220.9 \\
\hline & $75 \%$ PVA & 94.9 & 225 \\
\hline \multirow{5}{*}{$\begin{array}{l}10 \% \text { PVA and } 5 \% \text { gelatin } \\
\text { blend (1FT) }\end{array}$} & $80 \%$ PVA & 75.6 & 226.0 \\
\hline & $60 \% P V A$ & 75.3 & 224.2 \\
\hline & $40 \%$ PVA & 69.3 & 220.5 \\
\hline & $20 \%$ PVA & 74.7 & 218.2 \\
\hline & $0 \%$ PVA & 190.7 & No peak \\
\hline
\end{tabular}

of PVA/PVP blends decreased with increasing concentration of PVA; this could be due to the fact that PVA has a lower $T_{g}$ than that of PVP and hence decreases $T_{g}$ values of the blends as concentration of PVA is increased. $T_{g}$ temperatures of PVA: PVP blends were comparable to those reported by Cauich-Rodriguez et al. [22].

From the thermal analysis of PVA: gelatin blends, the measurements of $T_{g}$ indicate an increase in comparison to PVA $10 \%(\mathrm{w} / \mathrm{v})$ thus indicating that materials have undergone some crosslinking. $T_{g}$ temperatures of gelatin have been reported to be around the range of $180^{\circ} \mathrm{C}-210^{\circ} \mathrm{C}$ and represent the blocks of imino acids such as proline and hydroxyproline and amino acids such as glycine [19]. The blends showed $T_{m}$ peaks attributable to PVA ranging from 218 (20PVA1FT) to $226^{\circ} \mathrm{C}$ (80PVAlFT).

3.4. Tensile Strength of the Hydrogels. The tensile properties of the differently crosslinked gels were characterised by the ultimate tensile strength (UTS) and the Young's modulus of the hydrated gels. Figure 4 shows the effect of the different treatments to enable physical crosslinking in the PVA gels. The figure clearly indicates that the UTS increases with increasing concentration of PVA as expected with no significant difference between the $1 \mathrm{FT}$ and the cumulative $\mathrm{AD}$ and FT films; however, air drying on its own yielded the weakest gels. The wet tensile properties observed in this study

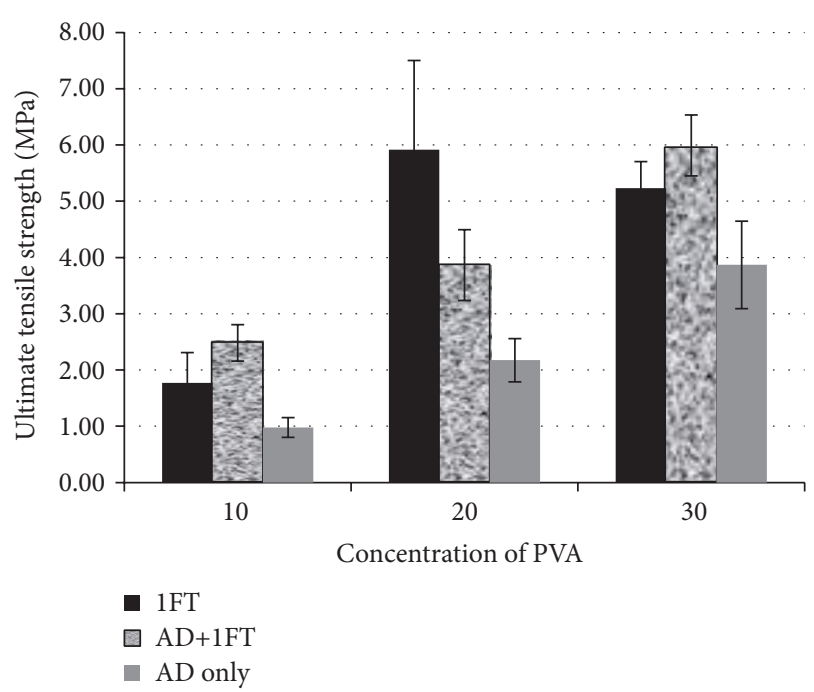

Figure 4: A comparison of the tensile strengths (uniaxial tensile tests) of PVA at equilibrium hydration after one cycle freeze-thaw $(1 \mathrm{FT})$, air-dried and one cycle freeze-thaw $(\mathrm{AD}+1 \mathrm{FT})$, and air-dried (AD) films.

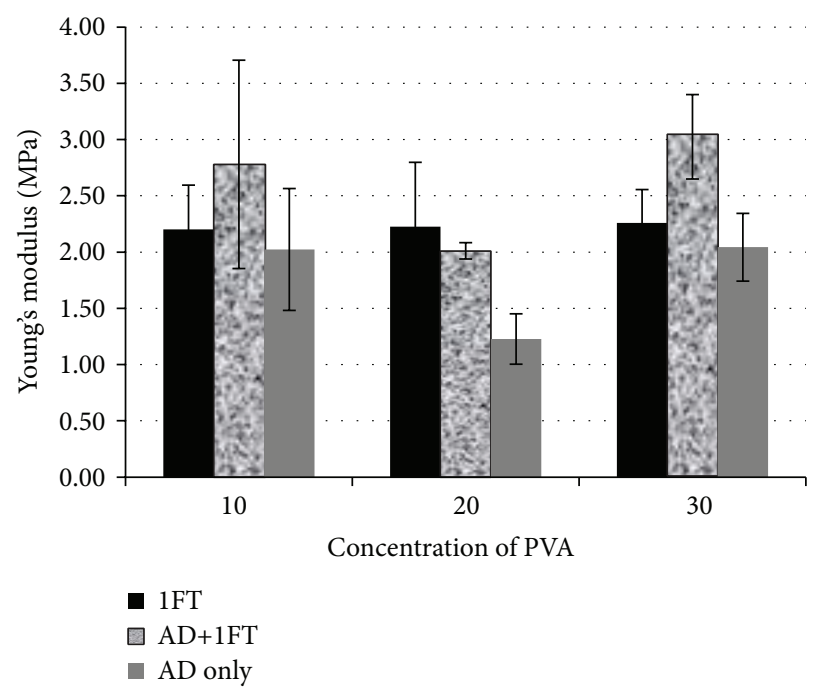

FIGURE 5: A comparison of the Young's modulus of PVA at equilibrium hydration after one cycle freeze-thaw (1FT), air-dried and one cycle freeze-thaw $(\mathrm{AD}+1 \mathrm{FT})$, and air-dried $(\mathrm{AD})$ films.

were much higher than the values reported in a study dedicated to creating PVA hydrogels using a photo-crosslinking approach [4]. The tensile modulus is shown in Figure 5 with a clear indication that the cumulative air-drying and $1 \mathrm{FT}$ lead to higher modulus for the $10 \%, 20 \%$, and $30 \%$ PVA hydrogels. The tensile strength and Young's modulus of the hydrated PVA-PVP and PVA-gelatin blends prepared by the AD+1FT method are shown in Figures 6 and 7, respectively, which show that higher PVA content yielded superior tensile strength. At this stage only the AD+1FT method was used to prepare the films as they clearly yielded the stronger gels. The result of the tensile testing showed that the higher EWC of the blend films was detrimental to the tensile properties 


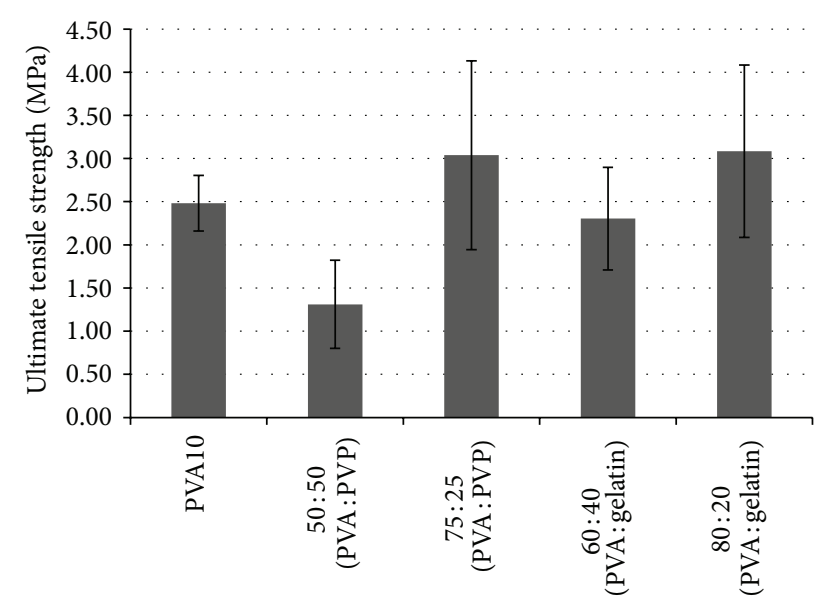

Figure 6: A comparison of the tensile strength (uniaxial tensile tests) of PVA blends with PVP and gelatin at equilibrium hydration after one cycle freeze-thaw (AD+1FT) films.

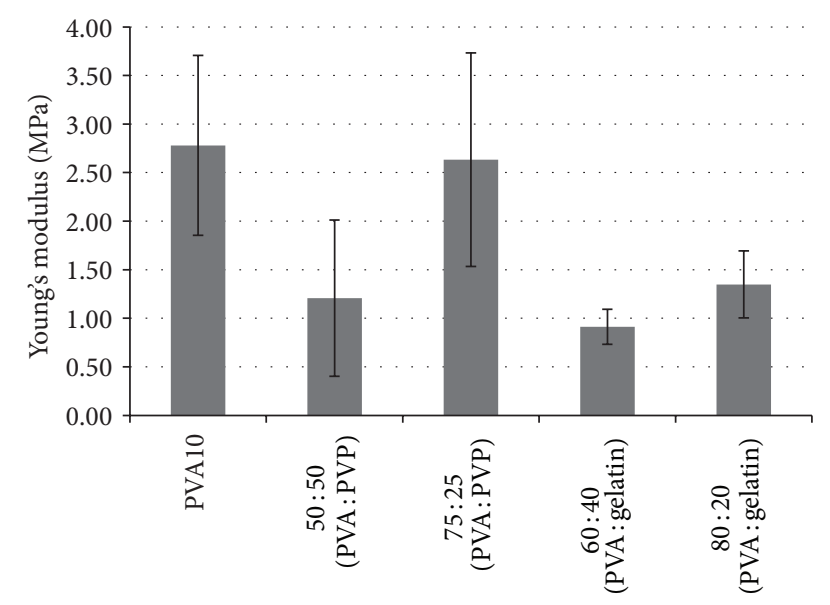

Figure 7: A comparison of the Young's Modulus of PVA blends with PVP and gelatin at equilibrium hydration after one cycle freeze-thaw (AD+1FT) films.

of PVA when freeze thawed but when air-dried it increased the stiffness of PVA significantly. The lower mechanical properties under wet conditions could be attributed to the increase in amorphous regions due to PVP's bulky side groups or the dilution of PVA or a combination of both factors. The tensile properties of the PVA blends with both PVP and gelatin indicate that they are sufficiently strong enough to be used for tissue engineering applications such as skin.

3.5. Conclusion. The study showed that the concentration of PVA clearly had an effect on the degree of crosslinking with air drying in conjunction with freeze-thawing yielding superior gels. The blends with gelatin or PVP increased the EWC of the hydrogels, however, which also had a detrimental effect on the mechanical properties. It was clear that hydrogels with better mechanical properties were obtained by using the combination of air-drying and freeze-thawing for creating blends, and thus this process will be used in our future work.

\section{Conflict of Interests}

The authors declare that there is no conflict of interests regarding the publication of this paper.

\section{Acknowledgments}

The authors would like to thank the University of Botswana School of Medicine for funding Shathani Nkhwa and King's College London Medical School studentship for funding Kristo Fernando Lauriaga.

\section{References}

[1] A. S. Hoffman, "Hydrogels for biomedical applications," Advanced Drug Delivery Reviews, vol. 54, no. 1, pp. 3-12, 2002.

[2] M.-H. Alves, B. E. B. Jensen, A. A. A. Smith, and A. N. Zelikin, "Poly(vinyl alcohol) physical hydrogels: new vista on a long serving biomaterial," Macromolecular Bioscience, vol. 11, no. 10, pp. 1293-1313, 2011.

[3] J. L. Drury and D. J. Mooney, "Hydrogels for tissue engineering: scaffold design variables and applications," Biomaterials, vol. 24, no. 24, pp. 4337-4351, 2003.

[4] R. H. Schmedlen, K. S. Masters, and J. L. West, "Photocrosslinkable polyvinyl alcohol hydrogels that can be modified with cell adhesion peptides for use in tissue engineering," Biomaterials, vol. 23, no. 22, pp. 4325-4332, 2002.

[5] C. R. Nuttelman, S. M. Henry, and K. S. Anseth, "Synthesis and characterization of photocrosslinkable, degradable poly(vinyl alcohol)-based tissue engineering scaffolds," Biomaterials, vol. 23, no. 17, pp. 3617-3626, 2002.

[6] L. Yao, T. W. Haas, A. Guiseppi-Elie, G. L. Bowlin, D. G. Simpson, and G. E. Wnek, "Electrospinning and stabilization of fully hydrolyzed poly(vinyl alcohol) fibers," Chemistry of Materials, vol. 15, no. 9, pp. 1860-1864, 2003.

[7] I. R. Oviedo, N. A. N. Mendez, M. P. G. Gomez, H. C. Rodriguez, and A. R. Martinez, "Design of a physical and nontoxic crosslinked poly(vinyl alcohol) hydrogel," International Journal of Polymeric Materials, vol. 57, no. 12, pp. 1095-1103, 2008.

[8] E. Otsuka and A. Suzuki, "A simple method to obtain a swollen PVA gel crosslinked by hydrogen bonds," Journal of Applied Polymer Science, vol. 114, no. 1, pp. 10-16, 2009.

[9] Y. Liu, L. M. Geever, J. E. Kennedy, C. L. Higginbotham, P. A. Cahill, and G. B. McGuinness, "Thermal behavior and mechanical properties of physically crosslinked PVA/Gelatin hydrogels," Journal of the Mechanical Behavior of Biomedical Materials, vol. 3, no. 2, pp. 203-209, 2010.

[10] Y. Liu, N. E. Vrana, P. A. Cahill, and G. B. McGuinness, "Physically crosslinked composite hydrogels of PVA with natural macromolecules: structure, mechanical properties, and endothelial cell compatibility," Journal of Biomedical Materials Research B: Applied Biomaterials, vol. 90, no. 2, pp. 492-502, 2009.

[11] G. Leone, M. Consumi, G. Greco et al., "A PVA/PVP hydrogel for human lens substitution: synthesis, rheological characterization, and in vitro biocompatibility," Journal of Biomedical Materials Research B: Applied Biomaterials, vol. 97, no. 2, pp. 278-288, 2011.

[12] A. Rogojanu, E. Rusu, N. Olaru, M. Dobromir, and D. O. Dorohoi, "Development and characterization of poly(vinyl alcohol) 
matrix for drug release," Digest Journal of Nanomaterials and Biostructures, vol. 6, no. 2, pp. 809-818, 2011.

[13] Z. I. Ali, F. A. Ali, and A. M. Hosam, "Effect of electron beam irradiation on the structural properties of PVA/ $\mathrm{V}_{2} \mathrm{O}_{5}$ xerogel," Spectrochimica Acta A: Molecular and Biomolecular Spectroscopy, vol. 72, no. 4, pp. 868-875, 2009.

[14] S. Gamal El Bahy, E. -S.M. -S, Abdel Aziz Mahmoud, and M. Noha Gweily, "Preparation and characterization of poly vinyl alcohol/gelatin blends," Journal of Applied Sciences, vol. 8, no. 7, pp. 3544-3551, 2012.

[15] W. H. Eisa, Y. K. Abdel-Moneam, A. A. Shabaka, and A. E. M. Hosam, "In situ approach induced growth of highly monodispersed Ag nanoparticles within free standing PVA/PVP films," Spectrochimica Acta A: Molecular and Biomolecular Spectroscopy, vol. 95, pp. 341-346, 2012.

[16] R. Yin, Y. Huang, C. Huang, Y. Tong, and N. Tian, "Preparation and characterization of novel gelatin/cerium (III) fiber with antibacterial activity," Materials Letters, vol. 63, no. 15, pp. 13351337, 2009.

[17] J. H. Muyonga, C. G. B. Cole, and K. G. Duodu, "Fourier transform infrared (FTIR) spectroscopic study of acid soluble collagen and gelatin from skins and bones of young and adult Nile perch (Lates niloticus)," Food Chemistry, vol. 86, no. 3, pp. 325-332, 2004.

[18] J. H. Muyonga, C. G. B. Cole, and K. G. Duodu, "Characterisation of acid soluble collagen from skins of young and adult Nile perch (Lates niloticus)," Food Chemistry, vol. 85, no. 1, pp. 81-89, 2004.

[19] A. K. Bajpai and R. Saini, "Preparation and characterization of biocompatible spongy cryogels of poly(vinyl alcohol)-gelatin and study of water sorption behaviour," Polymer International, vol. 54, no. 9, pp. 1233-1242, 2005.

[20] X. Liu, G. Fussell, M. Marcolongo, and A. M. Lowman, "Characterization of associating hydrogels of poly(vinyl alcohol) and poly(vinyl pyrrolidone)," Journal of Applied Polymer Science, vol. 112, no. 1, pp. 541-549, 2009.

[21] S. N. Cassu and M. I. Felisberti, "Poly(vinyl alcohol) and poly(vinyl pyrrolidone) blends: miscibility, microheterogeneity and free volume change," Polymer, vol. 38, no. 15, pp. 3907-3911, 1997.

[22] J. V. Cauich-Rodriguez, S. Deb, and R. Smith, "Characterization of hydrogel blends of poly(vinyl pyrrolidone) and poly(vinyl alcohol-vinyl acetate)," Journal of Materials Science: Materials in Medicine, vol. 7, no. 5, pp. 269-272, 1996. 

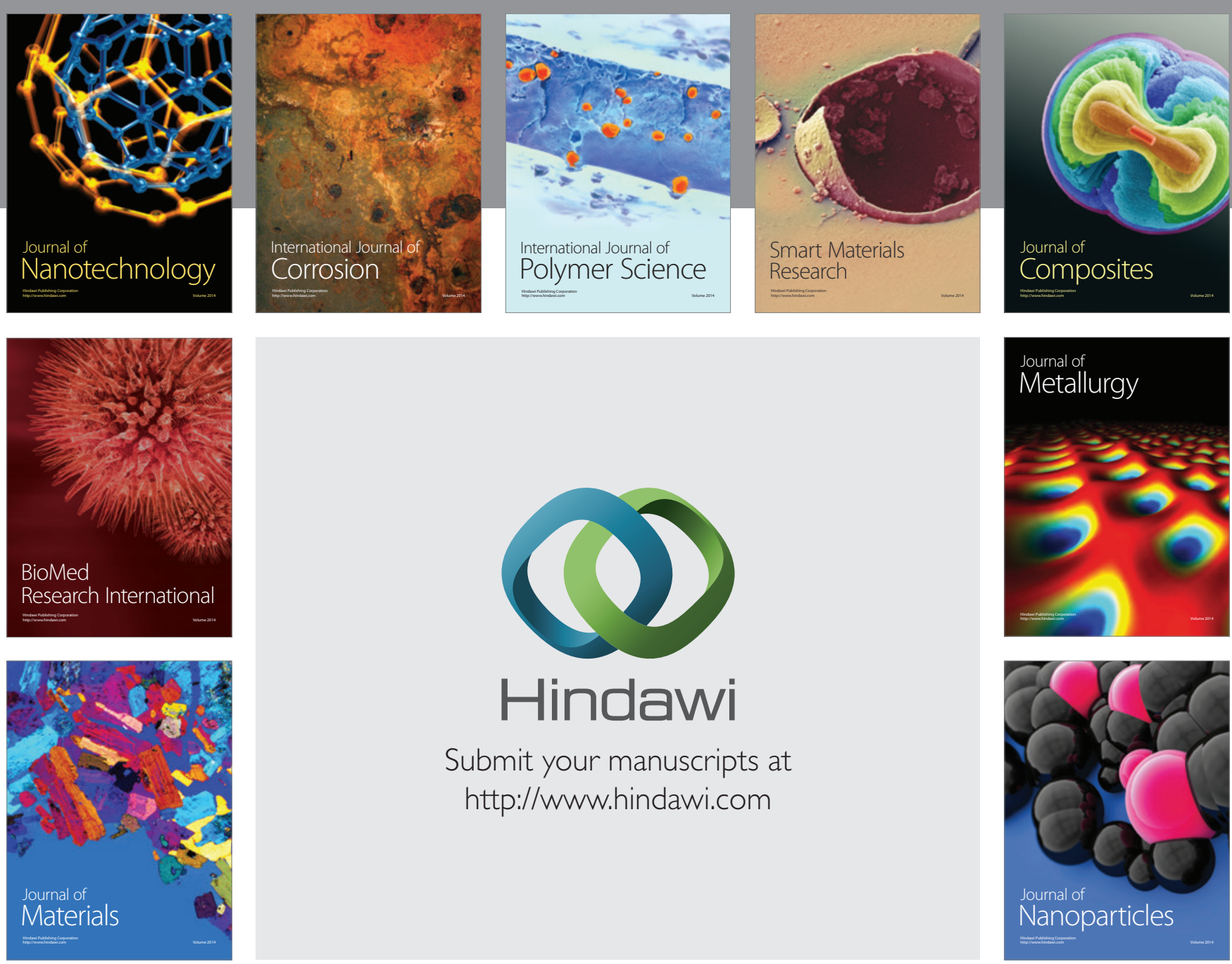

Submit your manuscripts at http://www.hindawi.com
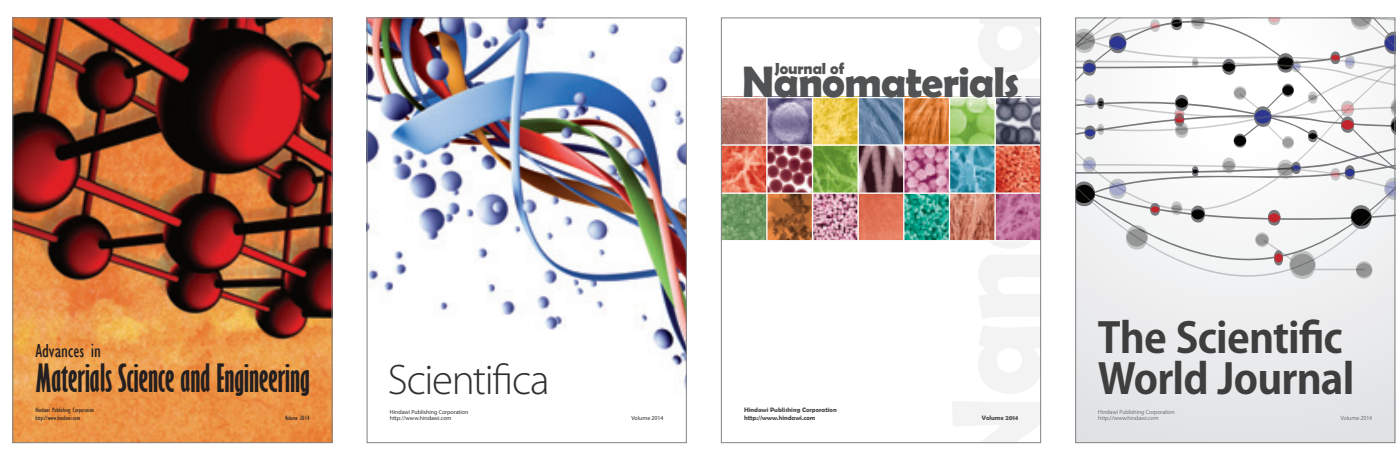

\section{The Scientific World Journal}
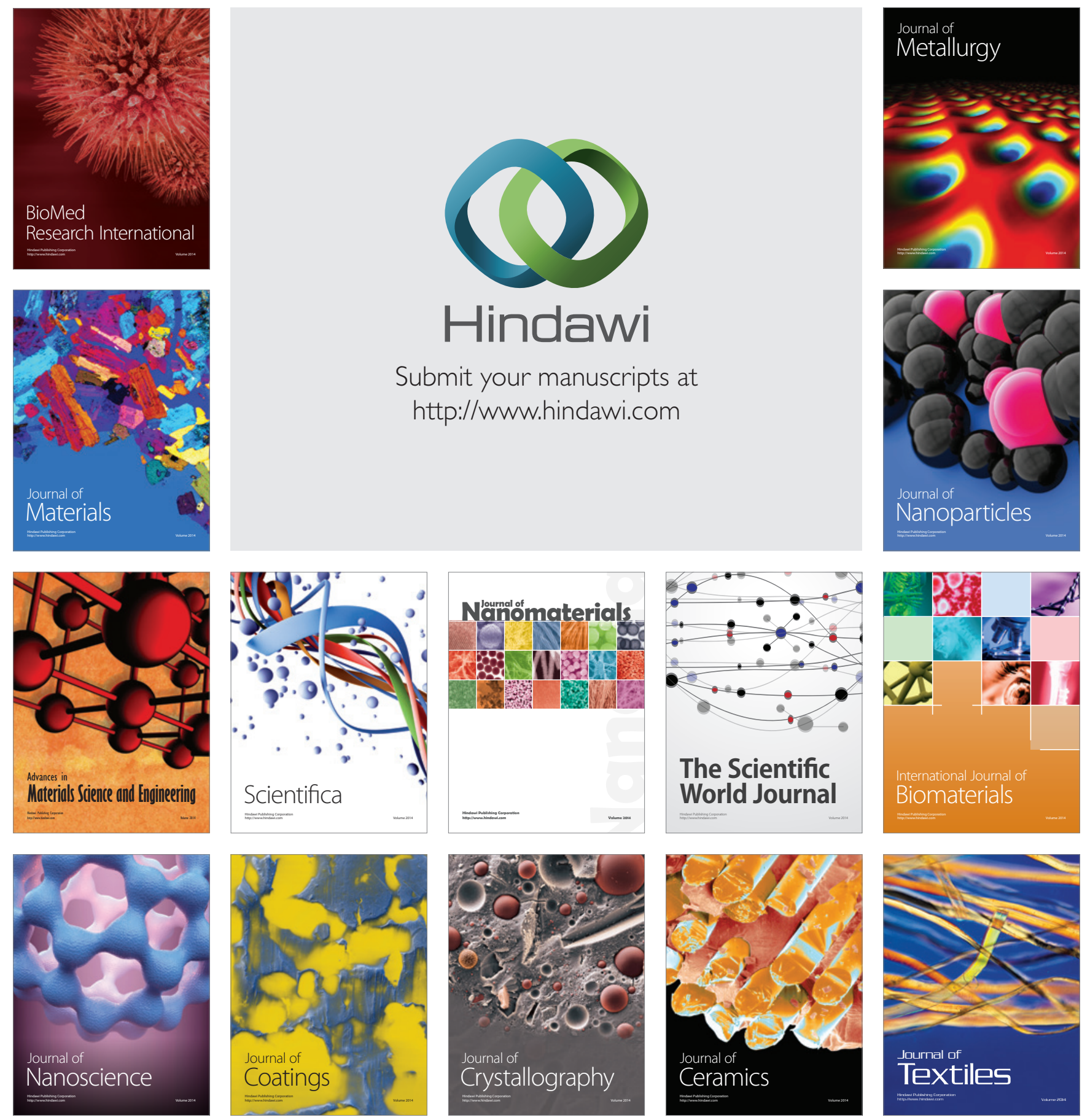